\title{
A Laplace transform solution for tracer tests in a radially convergent flow field with upstream dispersion
}

\author{
Jui-Sheng Chen ${ }^{a}$, Chen-Wuing Liu ${ }^{\mathrm{a}, *}$, Chia-Shyun Chen ${ }^{\mathrm{b}}$, Hun-Der $\mathrm{Yeh}^{\mathrm{c}}$ \\ 'Department of Agricultural Engineering, National Taiwan University, Taipei 10617, Taiwan, ROC \\ 'Institute of Applied Geology, National Central University, Taiwan, ROC \\ 'Institute of Environmental Engineering, National Chiao-Tung University, Taiwan, ROC
}

Received 25 September 1994; accepted 29 October 1995

\begin{abstract}
When tracers are introduced into an injection borehole, noticeable concentration gradients at the injection well may cause a backward spreading of the initial plume during radially convergent tracer tests. Based on this concept a non-rigorous mathematical model is developed to estimate the effect of backward spreading. The injection well with an instantaneous slug input is treated as a mathematical source and the initial plume at the injection well is allowed to move upstream. The model assumes that advection and longitudinal dispersion are the transport mechanisms in a radially converging flow field. The Laplace transform solution for solute concentration in an infinite porous medium is obtained using the method of Green's function. Breakthrough curves are computed by numerically inverting the Laplace transform solution. As compared with the solution of Moench, it is concluded that the presence of backward movement of initial plume yields a decrease of peak concentration and spreading out of breakthrough curve tails. This effect is significant for small Peclet numbers and can be neglected for large Peclet numbers. A field tracer test is carried out to demonstrate the applicability of the model. The experimental data are fitted with the type curves of this study, and those of Moench's study, to determine dispersivity and aquifer porosity. The results show that dispersivity values estimated by matching the two type curves are different. Because it neglects backward dispersion, Moench's solution overestimates the dispersivity and effective aquifer porosity.
\end{abstract}

\section{Introduction}

As the dispersive properties of aquifers are believed to control the spreading of solutes, it is important to accurately evaluate dispersion coefficients in the field. A forced-advective, field tracer test is usually employed to determine dispersivity and other hydrogeologic

\footnotetext{
* Corresponding author. 
parameters. The theoretical basis for tracer experiments conducted in a radial flow field has been available in the relevant literature for over three decades (Novakowski, 1992). A number of exact or approximate analytical solutions are available (Novakowski, 1992). Complete analytical solution of the radial dispersion equation for cylindrical coordinate systems is difficult to obtain because of the dependence of the coefficient of hydrodynamic dispersion on spatially varying velocity. Ogata (1958) first presented the closed-form analytical solution for the problem of divergent radial dispersion. Similar problems have been studied by Tang and Babu (1979), Chen (1985), Hsieh (1986) and Novakowski (1992).

For the problem of convergent dispersion, field and theoretical studies on the determination of effective porosity and longitudinal dispersivity have been reported by Lenda and Zuber (1970), Zuber (1974), Kreft et al. (1974) and Sauty (1977, 1978, 1980). Using a technique similar to that proposed by Sauty (1977), Carrera and Walters (1985) presented an algorithm for estimating the dispersivity of tracer tests in a convergent flow field. Guvanasen and Guvanasen (1987) presented approximate solutions for extraction tracers from a tracer ring created by an injection well. The closed-form analytical solution of aquifer decontamination by a single withdrawal well was given by Chen and Woodside (1988). Moench (1989) suggested that the injection well can be considered as an input boundary, and a Laplace transform solution for concentration in a pumped well was obtained for tracer tests in a converging flow field. The input boundary approach implies that no dispersive flux is allowed upstream of the injection well. That is, if solute is injected at a point, it should not move backward. However, it was found by Chen and Woodside (1988) that if the initial condition presented a noticeable concentration gradient at the plume boundary, adverse dispersion against converging groundwater movement would cause spreading of solute beyond the original extent of the plume, during pumping. Regarding the condition to be imposed at the injection well as an input boundary by Moench (1989), as the tracer is injected into the injection borehole it generates a noticeable concentration gradient at the injection plume boundary, and some of the solute cannot be transported by advection; this leads the tracer to travel convergently toward the pumped well, and so it travels upstream. Moreover, in view of mechanical dispersion owing to variations in microscopic velocity in both magnitude and direction within each pore channel and from one channel to another, water molecules are forced to moved along tortuous flow paths which may be adverse to the average flow direction; as a result, solutes could spread upstream. A non-rigorous mathematical model is proposed to investigate the possible effects of upstream spreading of a plume. Using Green's function, an exact analytical solution in the Laplace domain for tracer concentration in infinite aquifer is derived. A rcal-time tracer breakthrough curve is obtaincd by numerical inversion. The solution is useful in analysing data from field tracer tests. To demonstrate applicability of the current model, a field tracer test was conducted at a site in northern Taiwan. Aquifer dispersivity and effective porosity determined from both the current model solution and Moench's solution were analysed to show the difference with and without upstream dispersion.

\section{Mathematical model and solutions}

The dispersion problem of a tracer test in a radially convergent flow field is considered. 


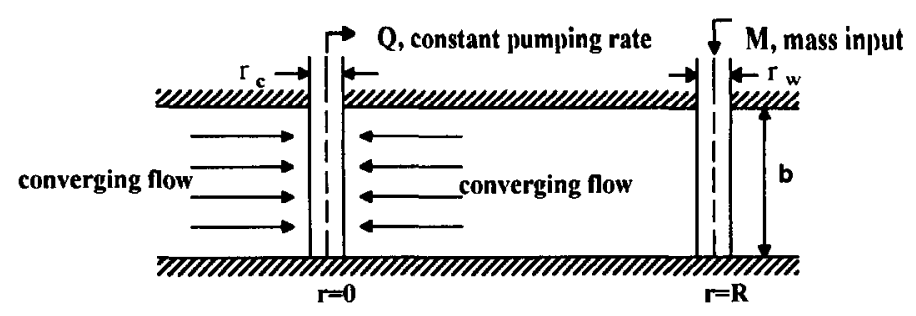

Fig. 1. Schematic diagram of radially convergent tracer test.

The conceptual model is illustrated in Fig. 1. The flow field is generated by a fully penetrating well of radius $r_{\mathrm{c}}$ located along the $z$-axis at $r=0$ and pumping fluid at a constant volume rate $Q$ from a homogeneous, isotropic aquifer of infinite horizontal extent. The average pore velocity, $V$, in the radial direction is described as

$$
V=-\frac{A}{r} \quad r_{\mathrm{c}} \leq r<\infty
$$

where $A=\frac{Q}{2 \pi b n_{\mathrm{e}}}$. The symbols $b$ and $n_{\mathrm{e}}$ refer to the aquifer thickness and effective
porosity.

At the start of a field test, a tracer is introduced instantaneously without disturbing the velocity distribution in the aquifer. The volume of the tracer plume at the injection well is small, allowing the slug injection to be treated as a Dirac delta, $\delta$, input. Assuming mechanical dispersion occurs in accordance with Fick's law and the dispersion coefficient is proportional to the velocity, the governing equation for the radially convergent dispersion with instantaneous slug injection at the injection well can be formulated as

$$
\frac{a_{\mathrm{L}} A}{r} \frac{\partial^{2} C}{\partial r^{2}}+\frac{A}{r} \frac{\partial C}{\partial r}+\frac{a_{\mathrm{L}} A}{r} \frac{\partial^{2} C}{\partial r^{2}}+\frac{M}{2 \pi R b n_{\mathrm{e}}} \delta(R-r)=\frac{\partial C}{\partial t}
$$

where $C$ is the concentration, $a_{\mathrm{L}}$ is the longitudinal dispersivity, $R$ is the radial distance between pumping well and injection well, and $M$ is the tracer mass.

The initial tracer concentration in the aquifer is assumed to be zero before the start of the test:

$$
C(r, 0)=0 \quad r_{\mathrm{c}} \leq r<\infty
$$

The withdrawal well is treated as a mathematical sink. The concentration inside the well bore is assumed to be in instantaneous equilibrium with the surrounding media. This implies that a zero concentration gradient exists at the interface between the well and its immediately adjacent aquifer at $r_{\mathrm{c}}$ during the pumping period. Therefore the boundary condition at $r_{\mathrm{c}}$ is prescribed as

$$
\frac{\partial C\left(r_{c}, t\right)}{\partial r}=0 \quad t>0
$$

Another boundary condition required for a unique solution to (2) is imposed at infinity by stating

$$
C(r \rightarrow \infty, t)=0
$$


Let $\tau$ be dimensionless time and $\rho$ be dimensionless radial distance; the governing Eq. (2) can then be re-expressed in the following form:

$$
\frac{1}{\rho} \frac{\partial^{2} C}{\partial \rho^{2}}+\frac{1}{\rho} \frac{\partial C}{\partial \rho}+C_{\mathrm{r}} \delta\left(\rho-\rho_{0}\right) \delta(\tau)=\frac{\partial C}{\partial \tau}
$$
where $\rho=\frac{r}{a_{\mathrm{L}}}, \rho_{0}=\frac{R}{a_{\mathrm{L}}}, \tau=\frac{A t}{a_{\mathrm{L}}^{2}}, C_{\mathrm{r}}=\frac{M}{2 \pi a_{\mathrm{L}} R b n_{\mathrm{e}}}$ and $C_{\mathrm{r}}$ is defined as the reference concen-
tration.

The initial and boundary conditions become

$$
\begin{aligned}
& C(\rho, 0)=0 \quad \rho_{\mathrm{c}} \leq \rho<\infty \\
& \frac{\partial C\left(\rho_{\mathrm{c}}, \tau\right)}{\partial \rho}=0 \quad \tau>0
\end{aligned}
$$

where $\rho_{\mathrm{c}}=\frac{r_{\mathrm{c}}}{a_{\mathrm{L}}}$

$$
C(\rho \rightarrow \infty, \tau)=0
$$

Application of the Laplace transformation with respect to $\tau$ of Eq. (6)-(9) yields

$$
\begin{aligned}
& \frac{1}{\rho} \frac{\mathrm{d}^{2} G}{\mathrm{~d} \rho^{2}}+\frac{1}{\rho} \frac{\mathrm{d} G}{\mathrm{~d} \rho}-p G=-C_{\mathrm{r}} \delta\left(\rho-\rho_{0}\right) \\
& \frac{\mathrm{d} G(\rho, p)}{\mathrm{d} \rho}=0 \quad \text { at } \rho_{\mathrm{c}} \\
& G(\rho, p)=0 \quad \rho \rightarrow \infty
\end{aligned}
$$

where $p$ is the Laplace transform parameter and $G$ is the Laplace transform of $C$ as defined by

$$
G(\rho, p)=\int_{0}^{\infty}(\rho, \tau) \cdot \mathrm{e}^{-p \tau} \mathrm{d} \tau
$$

Because Eq. (10) is an inhomogeneous differential equation, its complete solution involves a particular solution and a homogeneous solution. By converting Eq. (10) into the self-adjoint form and using Green's function, the complete solution is determined (detailed derivation is given in Appendix A).

The Laplace transform solution for the problem may be rewritten as

$$
\begin{aligned}
G= & \pi C_{\mathrm{r}} \rho_{0} p^{-\frac{1}{3}} \exp \left(\frac{\rho_{0}-\rho}{2}\right)\left\{-X \cdot A i\left(z_{0}\right) A i(z)+H\left(\rho-\rho_{0}\right) B i\left(z_{0}\right) A i(z)\right. \\
& \left.+\left[1-H\left(\rho-\rho_{0}\right)\right] A i\left(z_{0}\right) B i(z)\right\}
\end{aligned}
$$

where $X=\frac{2 p^{\frac{1}{3}} B i^{\prime}\left(z_{c}\right)-B i\left(z_{c}\right)}{2 p^{\frac{1}{3}} A i^{\prime}\left(z_{c}\right)-A i\left(z_{c}\right)}, z=\rho p^{\frac{1}{3}}+\frac{1}{4} p^{-\frac{2}{3}}, H\left(\rho-\rho_{0}\right)$ is the Heaviside step function, 
and $A i(z)$ and $B i(z)$ are two linearly independent Airy functions (Abramowitz and Stegun, 1964).

\section{Solution evaluation and numerical result}

Analytic inversion of Eq. (13) may be possible but would probably lead to complex integrals. Therefore, numerical inversion of the solution is adopted. Numerous algorithms that have been successfully applied to numerically invert Laplace transform analytical solutions to groundwater flow and solute transport problems include the Stehfest (1970) algorithm (Moench and Ogata, 1984; Chen, 1985, 1986), the Talbot (1979) algorithm (Barker, 1982; Hodgkinson and Lever, 1983; Moench, 1989), the Crump (1976) algorithm (Barker, 1982; Chen, 1989), and the De Hoog et al. (1982) algorithm (Moench, 1991; Novakowski, 1992).

In this paper, the Crump technique was selected to perform the inversion of Eq. (13) because it provides good accuracy for a wide variety of functions and it performs reasonably well in the neighbourhood of a discontinuity (i.e. a sharp front) (Crump, 1976). The Crump method is based on a Fourier series approximation of the inverse function and trapezoidal integration of the Laplace inversion integral like that in the method proposed by Dubner and Abate (1968), but error is reduced because both the real and imaginary parts of the transformed function are utilized. The Laplace parameter $p$ needs to be declared as complex in computation when the Crump method is used. Based on the Crump algorithm, a FORTRAN subroutine DINLAP (International Mathematics and Statistics Library, Inc., 1987) combined with a subroutine package for evaluating Airy functions of complex arguments is used. It allows for evaluation of Eq. (13) for Peclet numbers up to 400 . For larger Peclet numbers the function being inverted has a steep front; the algorithm cannot handle rapidly varying functions. A large Peclet number implies that the rate of transport of tracer by advection is much larger than the rate of transport of tracer by dispersion. Such conditions rarely occur and can be handled well by neglecting the dispersion effect. Results obtained by numerical inversion using the Crump (1976) algorithm are compared with results studied by Moench (1989). A hypothetical case is defined for the purpose of comparison. The following parameters are used: distance between centres of wells $5 \mathrm{~m}$; pumping rate $2 \mathrm{~m}^{3} \mathrm{~min}^{-1}$; aquifer thickness $10 \mathrm{~m}$; porosity 0.2 ; injected mass $10 \mathrm{~kg}$; radius of pumping well $0.02 \mathrm{~m}$; dispersivity $a_{\mathrm{L}}=5,0.5$ and $0.05 \mathrm{~m}$ (that is to say, Peclet number of 1,10 and 100).

Fig. 2 shows a comparison between the analytical solution of Moench (1989) and the analytical solution of this study for various Peclet numbers under various hypothetical conditions. The arrival times of peak concentrations are closely matched, but the peak concentration in Moench's study is greater than that in the current study. This difference is only significant for small Peclet numbers (large dispersivity) and longer tails are also presented in the current study. This result is consistent with the assumption of backward spreading of the initial plume in this study. It can be explained as follows. As backward spreading of the plume is allowed, sume solutes move backward owing to noticeable concentration gradients at the injection well, or owing to tortuous flow paths, whereas some also move forward by advection. This phenomenon results in a decrease of peak 


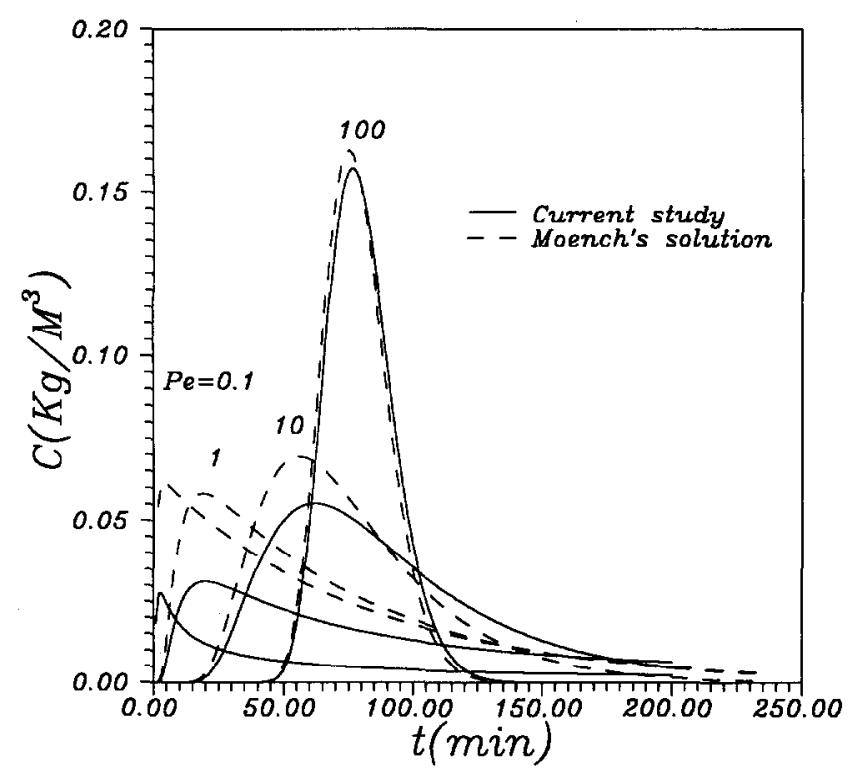

Fig. 2. Comparisons of dimensional breakthrough curves for the solution of the current model and the Moench (1989) solution in a hypothetical condition.

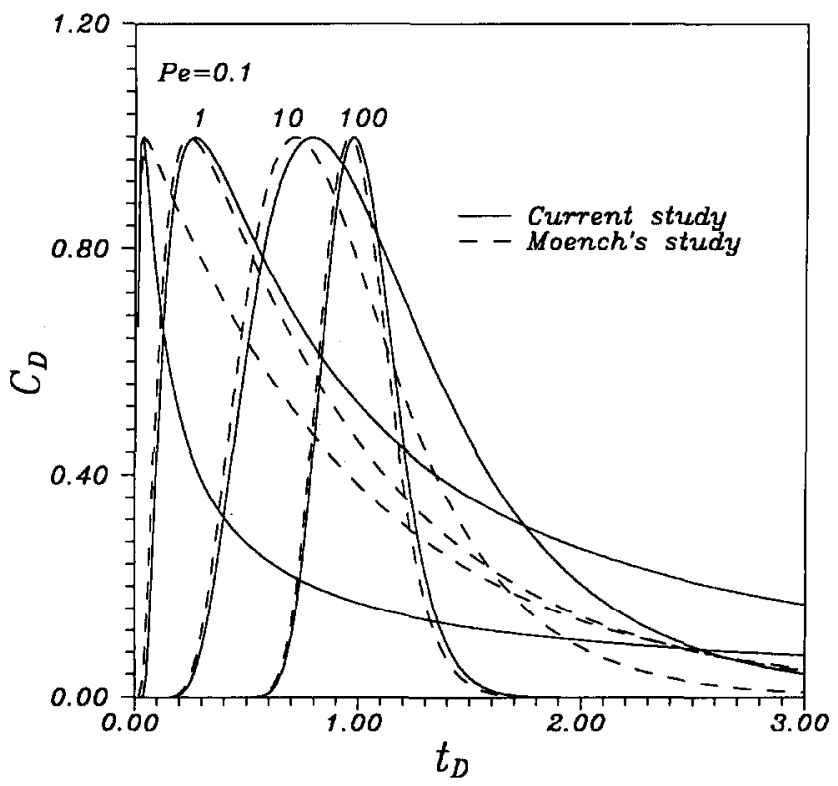

Fig. 3. Comparisons of dimensionless breakthrough curves (type curve) for the present study and the Moench study with concentration normalized with respect to maximum concentration and with the abscissa expressed as dimensionless time. 
concentration and a spreading-out of tails of breakthrough curves. As the dispersivity decreases, the influence of backward dispersion diminishes. By normalizing the concentration with respect to peak concentration and expressing real time as dimensionless time, $t_{\mathrm{D}}=\frac{Q t}{\pi R^{2} n_{\mathrm{e}} b}$, which had been used for the type curve developed by Sauty (1980), Fig. 3 is reconstructed from Fig. 2. It is shown that the two curves are nearly identical in the rising limb and exhibit a significant departure in the tails of curves for large Peclet numbers. If only the rising limb of the type curve is matched, the dispersivities estimated by the two are the same. However, if the spreading tail of the type curve is matched, the dispersivities estimated by the two may be different. The curves shown in Fig. 3 are useful for the determination of effective porosity and dispersivity of aquifer parameters.

\section{Field example}

\subsection{Site description}

To examine the applicability of the derived analytical solution, a field tracer test was conducted. The field site, Yenliao, is located on the northeast coast of Taiwan, where the Hsueshan Range subprovince of the Central Mountain Range extends to meet the Pacific Ocean. The Shuang-chi River is the major drainage within the general area of Yenliao site. The area can be divided into two parts: that north of the Shuang-chi River, and that to the south of the river. The northerly part, which includes the site, is characterized by ridges and valleys developed in a structurally complex sequence of sedimentary rocks. Drilling at the site revealed the presence of unconsolidated sediments from ground surface to a depth of $16 \mathrm{~m}$. The stratigraphic description from the drill log for the withdrawal well is depicted in Table 1 . The soils ranging from 1.7 to $6 \mathrm{~m}$ below the ground surface are slightly weathering. Rock appears at the well bottom. The saturated thickness of the formation around the test region is about $15.3 \mathrm{~m}$. Grain-size analyses were conducted to evaluate the sediment at the site. The topsoil, with specific gravity of 2.74 and void ratio of 0.39 , is composed of $40.9 \%$ gravel, $34.2 \%$ sand, and $24.9 \%$ silt and clay.

Table 1

Stratigraphy from the drill $\log$ at the well

\begin{tabular}{ll}
\hline Depth $^{\mathrm{a}}(\mathrm{m})$ & Description \\
\hline $0.0-1.7$ & Yellowish brown sandy soil \\
$1.7-4.2$ & Bluish grey, sandy shale \\
$4.2-7.8$ & Fine- to medium-grained sandstone \\
$7.8-11.4$ & Bluish grey shale intercalated with sandstone \\
$11.4-16.0$ & Dark grey shale occasionally with stone \\
16.0 & End of boring \\
\hline
\end{tabular}

\footnotetext{
${ }^{a}$ Depth from ground surface.
} 


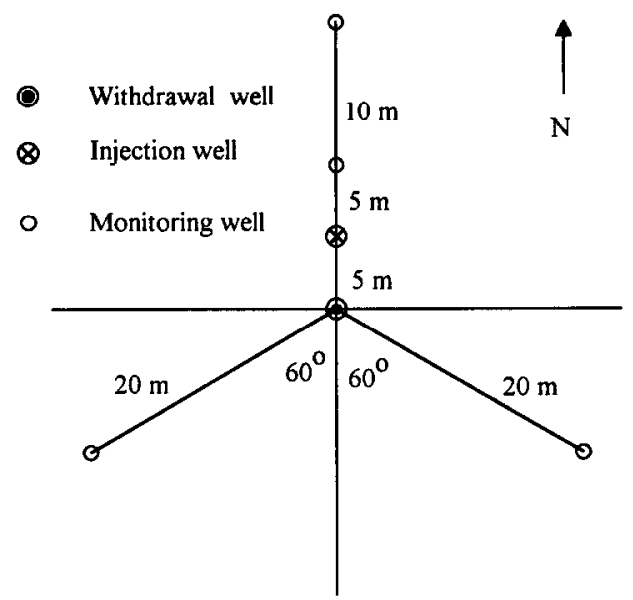

Fig. 4. The relative location of the well set.

\subsection{Apparatus}

The apparatus for conducting the field tracer tests included sampling devices and injection devices. One injection well, one withdrawal well and three monitoring wells were drilled for the tracer experiment. The locations of these wells are shown in Fig. 4. The withdrawal well and injection well were constructed of polyvinyl chloride (PVC) pipe of 4 in and 2 in diameter, respectively, and gravel packed to 6 in and 4 in diameter, respectively. The lengths of the screen for the withdrawal well and the injection well were $14.2 \mathrm{~m}$ and $14.4 \mathrm{~m}$, respectively. During the experiment, water was withdrawn by a submersible pump, and a flowmeter was used to record the pumping rate. Pressure transducers in conjunction with the In-Situ HERMIT 2000 data logger (HERMIT, Laramine, WY) were employed to measure and record the hydraulic head. The orange fluorescent dye, Rhodamine WT, was selected as tracer. It is considered one of the most useful tracers for quantitative studies, based on minimum detectability, photochemical and biological decay rates, and adsorption (Smart and Laidlaw, 1977). A tracer solution was injected into the injection well through Teflon tubing of $3 / 8$ in i.d. using a portable pump located at the surface. Water samples for monitoring tracer concentration were obtained from the withdrawal well using Teflon tubing connected to the discharge pipe line of the submersible pump. Dye concentrations were determined by a Turner Designs Model 10 Field Fluorometer (Turner Designs, Lincoln, $\mathrm{NE}$ ) in continuous flow-through mode and the results were stored automatically in the data logger.

\subsection{Experiment method}

A steady flow field was first developed after $10 \mathrm{~h}$ by continuous pumping at the withdrawal well with a constant flow rate of $101 \mathrm{~min}^{-1}$ before tracer injection. Monitoring of the hydraulic head at the pumping well, injection well and observation wells indicated that 


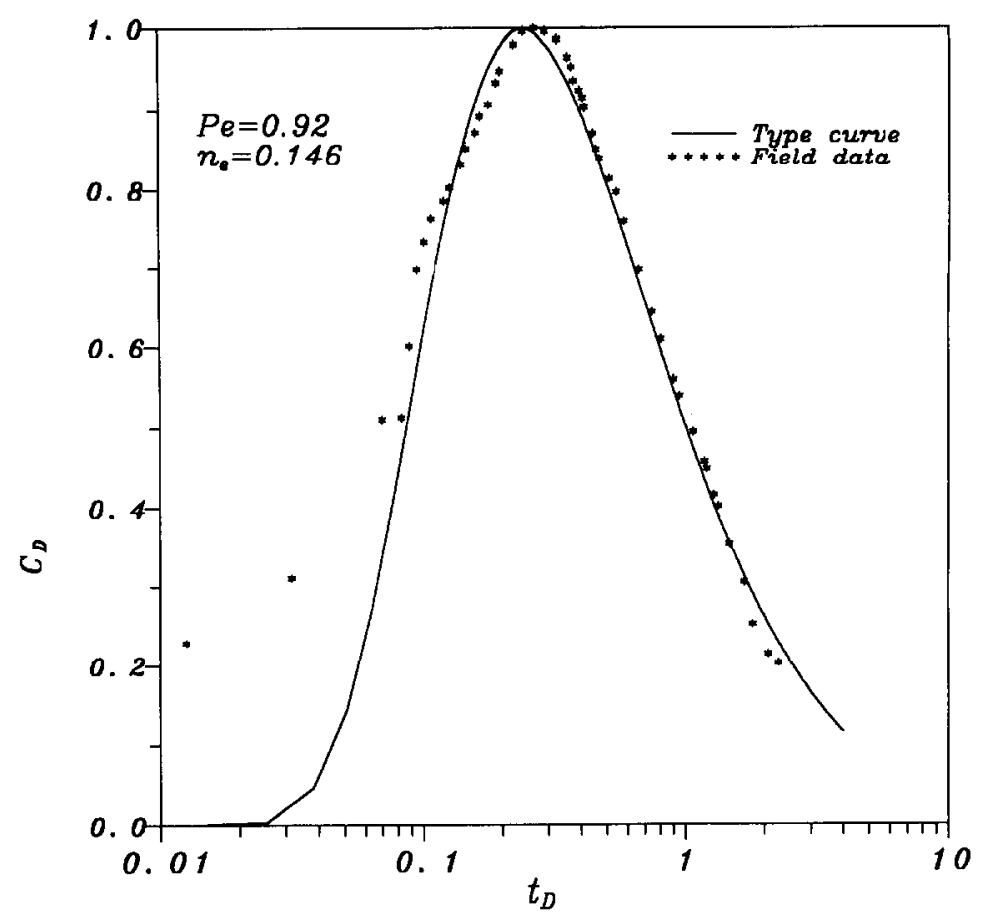

Fig. 5. The experiment data matched with the type curve of the current model.

a steady-state condition of the flow field was reached. The background concentration of Rhodamine WT was below the limit of detection for the fluorometer when analysing batch samples. Tracer solution (25 1) was mixed by combining $1.429 \mathrm{~g}$ of Rhodamine WT with water withdrawn from the aquifer. Instantaneous slug injection was accomplished by quickly draining the tracer solution through the tubing into the injection borehole by using an AccuWell PTP-100 Portable Pump (AccuWell, Sunnyvale, CA). To ensure that tracer was thoroughly mixed and uniformly distributed along the screen of the injection well in the injection borehole, the tubing outlet was raised smoothly and quickly after tracer introduction. After tracer introduction, water samples were collected at the withdrawal well and analysed by the fluorometer. The tracer test lasted for $11 \mathrm{~h}$. The estimated percent recovery of Rhodamine WT mass from the breakthrough curve is about $90 \%$.

\subsection{Data analysis}

The observed data were fitted to the analytical solution of Eq. (13) to determine apparent dispersivity on the basis of breakthrough curves. The concentrations observed at the withdrawal well were normalized relative to the peak concentration. The normalized concentrations were plotted semi-logarithmically against real time. As the experimental data were matched against the type curve, the Peclet numbers and the values of $\left(t, t_{\mathrm{D}}\right)$ were obtained (Sauty, 1980). Fig. 5 and Fig. 6 show the experiment results 


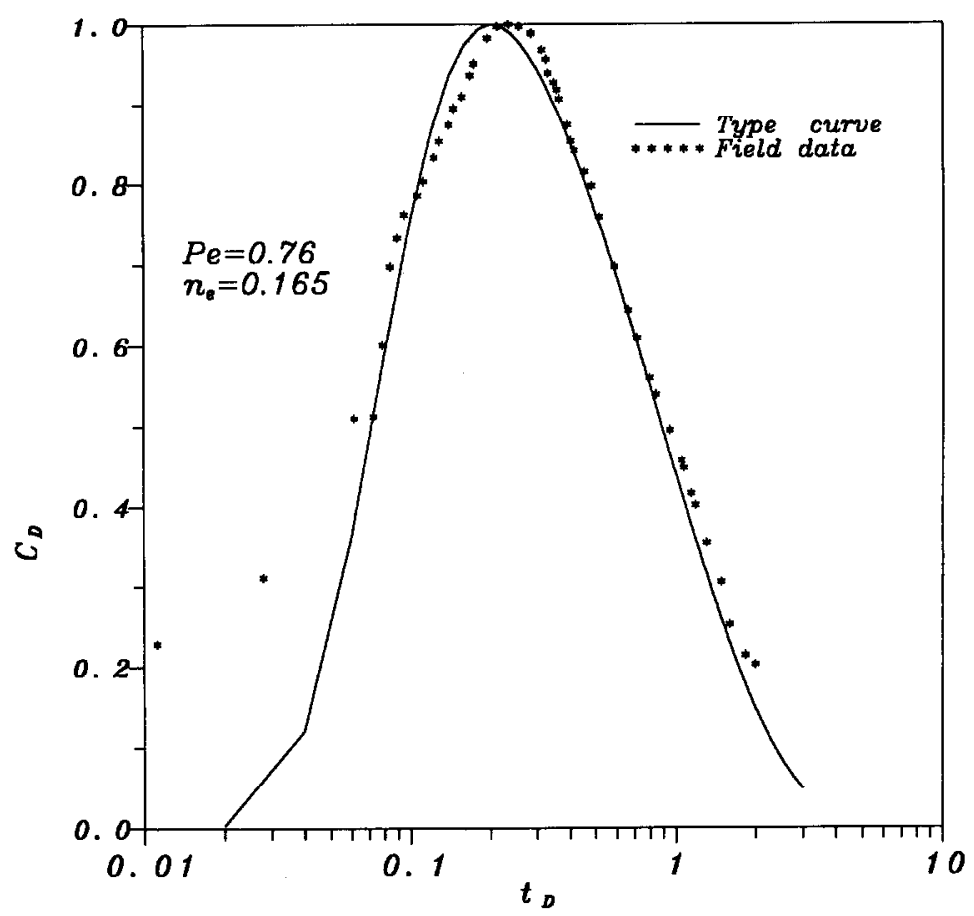

Fig. 6. The experiment data matched with the type curve of the Moench solution.

and the match obtained using Eq. (13) and the solution of Moench, respectively. It is estimated that Pe values were 0.92 and 0.76 for the two matches. As the backward dispersion will increase the degree of spreading, to obtain the same concentration distribution the dispersivity estimated from the current breakthrough curve will be lower than Moench's solution. Apparent dispersivity and effective porosity were then computed from

$$
\begin{aligned}
& a_{\mathrm{L}}=\frac{R}{\mathrm{Pe}} \\
& n_{\mathrm{e}}=\frac{Q t}{\pi R^{2} b t_{\mathrm{D}}}
\end{aligned}
$$

Apparent dispersivities of $5.43 \mathrm{~m}$ and $6.57 \mathrm{~m}$ were found, and the estimated aquifer effective porosities were 0.146 and 0.165 for two matches of the current study and Moench's study, respectively. Because it neglects the backward dispersion, Moench's solution overestimates the apparent dispersivity and the effective porosity of the aquifer.

\section{Conclusion}

A mathematical model is developed to evaluate influence of backward spreading for the 
problem of convergent radial dispersion of a tracer. An analytic Laplace-domain solution is obtained and inverted by a numerical method. The solution is compared with the solution of Moench. The result shows that adverse spreading against a converging flow has an effect on the breakthrough curves for small Peclet numbers. For large Peclet numbers, the solutions are similar to Moench's result. The type curves generated in the study exhibits tailing and spreading behavior. If only the rising limbs of the type curves are used for curve matching, the values of effective porosity and dispersivity estimated from the two methods are similar. If the spreading tail of the type curve is chosen to match, the dispersivity estimated by the two methods is different. The present solution is simpler than the solution derived by Moench, and the two solutions are shown graphically to be equivalent for large Peclet numbers.

\section{Acknowledgements}

Type curves of Moench's solution presented in this paper were generated with the FORTRAN program provided by Alan Moench. We highly appreciated his kind offering.

\section{Appendix A}

In this Appendix the solution of Eq. (10) subjected to boundary conditions Eq. (11) and Eq. (12) is derived. Since the particular solution is not readily known, Eq. (10) is first converted to a self-adjoint form, as

$$
\frac{\mathrm{d}^{2} G_{1}}{\mathrm{~d} \rho^{2}}-\left(\rho p+\frac{1}{4}\right) G_{1}=-F(\rho)
$$

where

$$
\begin{aligned}
& G_{1}=e^{\frac{\rho}{2}} G \\
& F(\rho)=\rho e^{\frac{\rho}{2}} C_{r} \delta\left(\rho-\rho_{0}\right)
\end{aligned}
$$

Expression of boundary conditions Eq. (11) and Eq. (12) in terms of $G_{1}$ are

$$
\begin{aligned}
& \frac{\mathrm{d} G_{1}}{\mathrm{~d} \rho}-\frac{1}{2} G_{1}=0 \text { at } \rho_{c} \\
& G_{1} \sim O\left(e^{-\frac{e}{2}}\right) \rho \rightarrow \infty
\end{aligned}
$$

Eq. (A1), subjected to Eq. (A4) and Eq. (A5) is a regular Sturm-Louiville problem, of which the general solution is

$$
G_{1}(\rho, p)=\int_{\rho_{c}}^{\infty} g(\rho, p, \xi) F(\xi) \mathrm{d} \xi
$$

where $\xi$ is a parameter varying between $\rho_{\mathrm{c}}$ and $\infty$. In Eq. (A6), $\mathrm{g}(\rho, \mathrm{p}, \xi)$ is the Green's function for the problem defined by Eqs. (A1), (A4) and (A5). By referring to the 
procedures given by Chen and Woodside (1988), the Green's function is

$$
g(\rho, p, \xi)= \begin{cases}g_{1}=\left(\pi / p^{\frac{1}{3}}\right) A i(s)[B i(z)-X A i(z)] & \text { if } p_{c} \leq \rho<\xi \\ g_{2}=\left(\pi / p^{\frac{1}{3}}\right) A i(z)[B i(s)-X A i(s)] & \text { if } \xi \leq \rho<\infty\end{cases}
$$

where

$$
\begin{aligned}
& s=p^{\frac{1}{3}}\left(\xi+\frac{1}{4 p}\right) \\
& z=p^{\frac{1}{3}}\left(\rho+\frac{1}{4 p}\right)
\end{aligned}
$$

The Laplace-domain solution Eq. (13) can be found by

$$
G(\rho, p)=e^{\frac{-\rho}{2}}\left\{\int_{\rho_{c}}^{\rho} g_{2}(\rho, p, \xi) F(\xi) \mathrm{d} \xi+\int_{\rho}^{\infty} g 1(\rho, p, \xi) F(\xi) \mathrm{d} \xi\right\}
$$

\section{References}

Abramowitz, M. and Stegun, I.A., 1964. Handbook of Mathematical Functions, Appl. Math. Ser. 55. National Bureau of Standards, Washington, DC.

Barker, J.A., 1982. Laplace transform solutions for solute transport in fissured aquifers. Adv. Water Resour., 5: 98-104.

Carrera, J. and Walters, G., 1985. Theoretical developments regarding simulation and analysis of convergent flow tracer test. Sandia National Laboratories, Tucson, AZ.

Chen, C.-S., 1985. Analytical and approximate solutions to radial dispersion from an injection well to a geological unit with simultaneous diffusion into adjacent strata. Water Resour. Res., 21(8): 1069-1076.

Chen, C.-S., 1986. Solutions to radionuclide transport from an injection well into a single fissure in a porous formation. Water Resour. Res., 22(2): 508-518.

Chen, C.-S., 1989. Solution approximating solute transport in a leaky aquifer receiving wastewater injection. Water Resour. Res., 25(1): 61-72.

Chen, C.-S. and Woodside, G.D., 1988. Analytical solution for aquifer decontamination by pumping. Water Resour. Res., 24(8): 1329-1338.

Crump, K.S., 1976. Numerical inversion of Laplace transforms using a Fourier Series approximation. J. Assoc. Comput. Mach., 23(1): 89-96.

De Hoog, F.R., Knight, J.H. and Stokes, A.N., 1982. An improved method for numerical inversion of Laplace transforms. SIAM J. Sci. Stat. Comput., 3(3): 357-366.

Dubner, H. and Abate, J., 1968. Numerical inversion of Laplace transforms by relating them to the finite Fourier cosine transform. J. Assoc. Comput. Mach., 15: 1115-1223.

Guvanasen, V. and Guvanasen, V.M., 1987. An approximate semi-analytical solution for tracer injection tests in a confined aquifer with a radially converging flow field and finite volume of tracer and chase fluid. Water Resour. Res., 23(8): 1607-1619.

Hodgkinson, D.P. and Lever, D.A., 1983. Interpretation of a field experiment on the transport of sorbed and nonsorbed tracers through a fracture in crystalline rock. Radioact. Waste Manage. Nucl. Fuel Cycle, 4(2): 129-158.

Hsieh, P.A., 1986. A new formula for the analytical solution of the radial dispersion problem. Water Resour. Res., 22(11): 1597-1605.

International Mathematics and Statistics Library, Inc., 1987. IMSL User's Manual, Vol. 2. IMSL, Inc., Houston, TX, pp. 756-758.

Kreft, A., Lenda, A., Turek, B., Zuber, A. and Czauderna, K, 1974. Determinatiun of effective porosities by the two-well pulse method. In: Isotope Techniques in Groundwater Hydrology, Vol. 2. Rep. STI/PUB/373, International Atomic Energy Agency, Vienna, pp. 295-311. 
Lenda, A. and Zuber, A., 1970. Tracer dispersion in groundwater experiments. In: Isotope Hydrology 1970. International Atomic Energy Agency, Vienna.

Moench, A.F., 1989. Convergent radial dispersion: a Laplace transform solution for aquifer tracer testing. Water Resour. Res., 25(3): 439-447.

Moench, A.F., 1991. Convergent radial dispersion. A note on evaluation of the Laplace transform solution. Water Resour. Res., 27(12): 3261-3264.

Moench, A.F. and Ogata, A., 1984. Analysis of constant discharge wells by numerical inversion of Laplace transform solutions. Water Resour. Monogr. Am. Geophys. Union, 9: 146-170.

Novakowski, K.S., 1992. The analysis of tracer experiments conducted in divergent radial flow fields. Water Resour. Res., 28(12): 3215-3225.

Ogata, A., 1958. Dispersion in porous media. Ph.D. Dissertation, Northwestern University, Evanston, IL.

Sauty, J.-P., 1977. Contribution a l'identification des parametres de dispersion dans les aquifers par l'interpr étation des expériences de tracage. D.Ing. Thesis, Univ. Sci. et Med. de Grenoble, Grenoble .

Sauty, J.-P., 1978. Identification des parametres du transport hydrodispersif dans les aquifers par interprétation de tracages en écoulement cylindrique convergent ou divergent. J. Hydrol., 39: 69-103.

Sauty, J.-P., 1980. An analysis of hydrodispersive transfer in aquifers. Water Resour. Res., 16(1): 145-158.

Smart, P.L. and Laidlaw, I.M.S., 1977. An evaluation of some fluorescent dyes for water tracing. Water Resour. Res., 13(1): 15-33.

Stehfest, H., 1970. Numerical inversion of Laplace transforms. Commun. ACM, 13: 47-49.

Talbot, A., 1979. The accurate numerical inversion of Laplace transforms. J. Inst. Math. Its Appl., 23: 97-120.

Tang, D.H. and Babu, D.K., 1979. Analytical solution of a velocity dependent dispersion problem. Water Resour. Res., 15(6): 1471-1478.

Zuber, A., 1974. Theoretical possibilities of the two well pulse method. In: Isotope Techniques in Groundwater Hydrology, Vol. 2. Rep. STI/PUB/373, International Atomic Energy Agency, Vienna, pp. 277-293. 